Revista de la red interuniversitaria de estudios sobre las literaturas rioplatenses contemporáneas en Francia

$10 \mid 2014$

El XIX en el XX

\title{
Conversaciones y reenvíos con Gabriela Cabezón
}

Cámara

\section{Nora Domínguez}

\section{OpenEdition}

Journals

Edición electrónica

URL: https://journals.openedition.org/lirico/1653

DOI: $10.4000 /$ lirico. 1653

ISSN: 2262-8339

Editor

Réseau interuniversitaire d'étude des littératures contemporaines du Río de la Plata

Referencia electrónica

Nora Domínguez, «Conversaciones y reenvíos con Gabriela Cabezón Cámara», Cuadernos LIRICO [En línea], 10 | 2014, Publicado el 15 marzo 2014, consultado el 21 septiembre 2021. URL: http:// journals.openedition.org/lirico/1653 ; DOI: https://doi.org/10.4000/lirico.1653

Este documento fue generado automáticamente el 21 septiembre 2021

\section{(c) $(1) \&$}

Cuadernos LIRICO está distribuido bajo una Licencia Creative Commons Atribución-NoComercialSinDerivar 4.0 Internacional. 


\title{
Conversaciones y reenvíos con Gabriela Cabezón Cámara
}

\author{
Nora Domínguez
}

Gabriela Cabezón Cámara se planta como narradora en el circuito editorial argentino en el 2008 con la publicación de La Virgen Cabeza. Entre el 2012 y 2013 publica su segunda novela Le viste la cara a Dios, luego Beya en tres formatos y tres soportes diferentes. Son textos provocadores que palpan el mundo de las orillas suburbanas, con personajes en situación de riesgos constantes, cuerpos moviéndose al compás de una familiarización de la violencia, lenguajes llevados hacia el grito o la injuria que hacen masa con una lengua que busca y rebusca en las referencias literarias otra réplica de la provocación. Su apuesta hace serie con otras que a lo largo del siglo XX miraron hacia esos relatos populares del XIX que le daban contenido, forma literaria y tonos plebeyos a la "barbarie". Entre esos pliegues, las novelas observan una ligazón constitutiva entre los terrenos de lo marginal, el devenir de las sexualidades y sus formas de resistencia a los poderes estatales.

\begin{abstract}
La Virgen cabezay Le viste la cara a Dios son dos novelas emplazadas en situaciones, espacios, universos, personajes, hablas del presente de Buenos Aires y el conurbano bonaerense. En ellas se respira y se lee una violencia actual, situada, que identifica y señala referencialidades muy reconocibles. En este sentido, las dos novelas parecen escritas en proximidad con esos enclaves donde se producen algunos hechos periodísticos, las crónicas del delito y de la marginalidad. Sin embargo no apuestan a la crónica, el testimonio o el relato periodístico ¿Cómo se deciden las voces y los tonos con los que se van a traer a escena estos materiales? ¿Cómo se trabaja la materia verbal que les va a dar forma literaria?

Las novelas se emplazan, efectivamente, en escenarios reconocibles y violentos, en relación con lo que suele ser la fuente principal del hecho periodístico, del policial. No apuesto a la crónica, el testimonio o el relato periodístico porque no me interesan los hechos en sí, no me interesa contar lo que efectivamente sucede, no me interesa esa relación con lo real : me interesa contar lo que eso me dispara, lo que podría ser, lo que quiero y lo que va sucediendo en la escritura misma. En este momento, por ejemplo, estoy terminando una novela cuya imagen inicial fue una foto en un diario : un hombre
\end{abstract}


en llamas en el centro del cuadro, los borceguíes de los policías que huían de él saliéndose del cuadro. Estaban desalojando un edificio en Neuquén y un chico, un hombre joven, "un canillita de 31 años", decía la nota, se prendió fuego en protesta. Eso pasó en 2000 o 2001. Me impactó la foto y seguí un poco la noticia : luego de la feroz protesta del canillita bonzo, el desalojo siguió con relativa normalidad. A los quince días, el hombre murió por las quemaduras. Hubo una batalla campal entre vecinos y policías. Otros quince días después, el gobierno de la provincia decidió devolverles las viviendas a los desalojados con la condición de que se casaran legalmente todas las parejas : la segunda foto de esta noticia era gente de un lado y otro de mesas que eran largas tablas montadas sobre caballetes bajo arroz cayendo como nieve. Y ahí se acabó la historia. Desde entonces le presto atención a los bonzos y llegué a tener algún -no mucho- conocimiento sobre el tema. La novela que estoy escribiendo cuenta la historia de una mujer, "una joven poeta de 30 años", dirían los diarios, que, luego de la inauguración de una muestra de arte, se va con la artista y un colega a tomar cocaína y whisky al departamento de la artista, en un edificio tomado. A los tres o cuatro días, tenían una gran piedra y muchas botellas, la policía llega a desalojar el edificio. Nuestra protagonista, completamente fuera de sí por la droga y el alcohol, amenaza con quemarse si los canas avanzan y avanzan nomás. Ella se prende. El desalojo sigue. Ella agoniza largamente, pero no muere. Por la difusión mediática que tiene su imagen de bonza, la filman cientos de personas cruzando la avenida en llamas, el juez que había decidido el desalojo da marcha atrás, devuelve a los okupas sus departamentos y además obliga al gobierno a darles un subsidio para dejar el edificio de punta en blanco. Como estos okupas son artistas, con ellos se inicia un movimiento artie de ocupación de viviendas: sus marchas y actos de resistencia son performances, van ganando popularidad, comienzan a negociar con punteros y gobiernos, se asocian con otras víctimas, terminan transando bastante, el gobierno los quiere de su lado, llegan a realizar una instalación en la Bienal de Venecia alrededor de la idea de sacrificio con la bonza como pieza central -consigue sobrevivir y los lidera- y otras cuantas cosas más. La relación con el hecho periodístico en este caso es la de punto de partida. La elección del tono y del narrador fue, como siempre, lo más difícil : como no sé para dónde va una historia mientras escribo, y tampoco me importa especialmente la línea argumental, es el punto de vista y el tono lo que decide todo, lo que hace avanzar la novela. A esta le di muchas vueltas hasta que llegué a una primera, habla la bonza-líder, que cuenta, al fin y al cabo es poeta, parte con base octosilábica, parte con base endecasilábica y parte sin ninguna base métrica. La novela se llamará El Romance de la Negra Rubia y saldrá publicada en marzo del 2014

¿Considerás que hay un imaginario nacional de escritura de la violencia al que no se puede renunciar y que evoca determinados nombres (El matadero, la refalosa, Martín Fierro, El fjord, Cadáveres) a pesar de sus singularidades y diferencias?

Es un imaginario al que yo no puedo renunciar. En términos de literatura, para mí son los textos fundamentales, esos cuya lectura me marcó un antes y un después, incluso cuando no podía pensar en términos de tradición ni de ruptura, cuando era una lectora más sencilla, por decirlo de algún modo. Desde que hice esas lecturas ya casi no puedo pensar la violencia sin referirla a esos textos : me la filtran, me la estructuran, me la llenan de leit motivs. La carne, su falta, la lucha por la achuras, el degüello del nene, la violación elidida, el degüello una vez más, pero esta vez intencional y del enemigo político, la fiesta, el erotismo bestial "para nosotros no es mengua el besarlos en la lengua", la leva, el ejército, el hambre, el indio, la cautiva, la muerte del niño 
destripado, el parto, la lluvia de golpes, la violación, el castigo por el sexo, por su falta y por su exceso, la matanza del amo, y, por fin, los cadáveres, esos que de no estar están en todas partes, incluso en el sexo, "en las conchitas de las pendejas". Son textos que ponen en juego poéticas poderosas, por eso fundan y marcan y se hacen inevitables.

Tanto El matadero en el siglo XIX como El fjord en el XX son textos armados sobre la disputa política, más o menos explícita, más o menos elusiva, pero sin duda coyuntural en ambos casos En tus novelas el enfrentamiento no se establece entre facciones o grupos políticos que disputan sobre "la patria", aunque, como esos textos disponés y distribuís violencias sexuales y verbales que podrían pensarse como para estatales (el prostíbulo en Beya) o contraestatales (la villa en La Virgen.) ¿Cómo situarías en tus novelas la política, u otras maneras de pensar de lo político ?

Lo político aparece como pugna, como una violencia que estructura a la sociedad y a la cual se intenta resistir. En mis textos no hay patria, no hay un todo que dominar ni un todo que contenga, no hay una idea de pertenencia a una Nación. En todo caso habría clases, pero no se representan como universales en el sentido de que están contenidas en la situación que se relata, no tienen más referencias que las que se describen, los personajes no se sienten parte de algo mucho más grande o en todo caso les parece distante, otro planeta, la política es lo que se practica ahí en el lugar en el que están, es una escala pequeña, no pasa del tamaño de una villa. El Estado, es cierto, no lo había pensado, sólo aparece como cómplice de los poderosos e incluso como generador de violencia a través de la policía. La resistencia se representa como fruto de lazos sociales de solidaridad, en La Virgen..., o como odio, en Beya. En los dos casos, es una práctica política de lo pequeño y lo inmediato, que se atiene a la situación concreta, al lugar en el que se está.

Sin embargo, la aparición de Beya estuvo acompañada no solo por la reunión habitual de una "presentación de libros" en una librería de la ciudad sino por una amplitud de presentaciones en distintos ámbitos y con diferentes grupos pero también por acciones de intervención pública : pintadas en la Feria del libro, escritura de murales contra la trata. ¿En qué medida te sentiste convocada, interpelada a participar e incluso a generar actos en contra de la injusticia política y social de la trata y esclavitud de personas ? ¿En qué medida percibiste que el texto se convertía en una acción de transmisión y construcción política?

En la medida en que nos interpelaban en ese sentido, no sólo algunos periodistas sino algunos políticos ; en algún momento hubiera preferido que no fuera así. Un escritor escribe un libro y, en el mejor de los casos, lo que sale es un libro bien escrito. Por momentos, cuando escribís algo que tiene una impronta política fuerte, te interpelan como si fueras Sartre, cómo si supieras qué hacer. Es medio raro y muy incómodo. El resto, por ejemplo pintar murales, es muy lindo de hacer, terminás hablando con gente que si no nunca, se acercan personas con las más diversas inquietudes, se tiene la sensación de agitar un poquito, hay algo del lazo con otros, con parte de una comunidad que se pone en acto en el intercambio, en la colaboración de la gente que se acerca, que se siente muy cálido.

Tu condición de periodista ¿de qué manera te obliga o te incita a mirar e involucrarte con los hechos sociales de una forma más concentrada o atenta ? Los materiales literarios que te interesa manipular y transformar (voces y personajes populares, espacios marginales, hablas de lo bajo) coinciden con los intereses de tu actividad periodística o tratás de que las dos actividades se mantengan en franjas diferenciadas.

No coinciden en absoluto: lo que yo hago como periodista es básicamente editar y editar notas de cultura dentro de lo que se entiende que eso es en un diario muy masivo como es Clarín. Por otra parte el periodismo, cuando se ejerce en un medio masivo, es 
algo muy pautado desde el lenguaje y desde lo ideológico, lo contrario a la literatura. Yo no tengo que hacer nada para que estén separados. Digamos que se cortan solos.

Podríamos pensar la literatura argentina como un álbum de escenas emblemáticas de la violencias que condensan momentos histórico-políticos, modos de escritura, capas divergentes de interpretaciones que fueron construyendo una historia literaria. Por ejemplo : la escena de la vejación del unitario en El matadero, en manos del grupo que lidera el degollador Matasiete y la escena final de El fjord donde el narrador y Sebas salen hacia la manifestación política con la bandera. Es decir, una escena de violencia extrema, otra que como desenlace llega después de la violencia pornográfica y radical en El fjord. En Beya es posible leer estos restos literarios, desde ya, transformados: el secuestro y el sometimiento a la esclavitud de la joven y su salida con disfraz de vengadora enarbolando la ametralladora asesina. ¿Qué podés decir sobre estas supervivencias literarias y su manipulación ficcional puestas al servicio de una justiciera versión femenina?

Sobreviven, sí, hay algo de Matasiete en el cafishio, algo de la violencia sexual de $\mathrm{El}$ fiord y de El niño proletario en Beya y también algo de la revancha de Sebas y el narrador en el uso que hace de su ametralladora. Más que justiciera, yo la llamaría resistente porque el uso que hace de la violencia es un poco más masivo de lo estrictamente necesario pero es lo que necesita para liberarse. El hecho de que el personaje sea mujer no me parece que cambie demasiado las cosas : puestos en situación de sometimiento y violación, el género da lo mismo, inmediatamente se transforma en femenino; todo violado es mujer, en un sentido. Seguro que alguien ya lo pensó y lo categorizó con más precisión, vos lo sabrás mejor que yo. La salida después de la matanza, que en el caso de Sebas y el narrador puede leerse apenas como un paréntesis para la violencia del poder que va de uno a otro en la pugna, en el caso de Beya es también una salida amarga, una condena : en un punto, de la violencia extrema no se sale.

Efectivamente, del mismo modo podría decirse toda cautiva es mujer. Hay una adhesión imaginaria de lo femenino al sometimiento que encierra otra modulación siniestra : si todo violado es mujer, toda mujer puede ser violada. Sin embargo, el texto en lugar de dejar el cuerpo de la víctima inerme como el cuerpo del torturado sobre las paredes del prostíbulo, desparrama sobre esas paredes, una voz de la conciencia que parece pedirle otra cosa. Cuerpo y voz se separan y es la voz en segunda persona, imperativa, demandante, exigente, violenta la que construye otra salida para la narración, otra economía para la lógica prostibularia. En esto veo un gesto político de inversión de las "fijezas patriarcales femeninas" y vale y mucho como imaginación literaria política y femenina. Prefiero esa imaginación y no la condena, esa violencia extrema que decís "no se sale". Y sin embargo en La Virgen Cabeza la deriva narrativa de los personajes parece otra.

Estoy completamente de acuerdo con todo lo que afirmás. No sé si me doy cuenta cómo podría seguir... Pruebo : LVC termina medio chistosamente; luego de construir otra forma de femineidad y de vínculo en todo el libro, al final vuelven los estereotipos, o eso dice una de las narradoras, Qüity, y sale corriendo tras Cleo, la travesti que fue padre biológico y es madre practicante (en el sentido del estereotipo, la que cocina, elige la ropa, etc). Qüity también era madre de la niña, pero de un modo más distante. Y cuando se entera de que Cleo se va, sale a buscarla para evitar ser cristalizada ahí, en el lugar de madre abandonada con una niña.

El uso de la segunda persona es para mí una de las fuerzas del texto, construye un tono penetrante, escandaloso que no da respiro. Hay entre esa voz y el personaje de la jovencita una alianza, en términos de Ludmer, entre voz y cuerpo que mezcla también registros : Io oral, lo bajo entrecruzado con las referencias literarias, tanto de los textos y autores que venimos nombrando como de los místicos españoles o las figuras más actuales de la teoría política, como el musulmán sobre el que piensa Agamben. ¿Qué podés decir de 
estos pasajes, saltos, superposiciones entre diferentes niveles culturales, sociales, de la lengua?

Lo que me pasa es que no los vivo como pasajes o saltos, son partes de mi experiencia. El lenguaje que uso tiene como materia prima muchísimo de mis lecturas y mucho de mi experiencia directa; no son materias que pueda separar sencillamente, se me mezclaron y se me superpusieron para siempre, creo, y desde siempre. Tal vez viví claramente la distancia entre los dos ámbitos lingüísticos cuando era una nena y todas las traducciones a las que tenía acceso, lo mío entonces era la Biblioteca Robin Hood de mi abuela, usaban el "tú", y por otra parte mi ámbito de pertenencia tenía menos recursos lingüísticos que los que transito ahora. Alguna vez el "vos" en un libro fue una novedad para mí, eso podría haber sido un salto. Después, por lo menos desde que pisé la facultad, se mezcló todo.

Sin duda, Le viste la cara a Dios o Beya es una novela sobre la trata de personas. Pero, el relato exige atravesar el guión del secuestro y de esta manera pasa a emparentarse con los relatos de secuestros y torturas de la dictadura y en segundo lugar, lo obliga a emplazarse en las lógicas prostibulares y aquí es donde podemos distinguir una larga tradición en la novela argentina y establecer otros vínculos. Sabemos que la figura de la prostituta ha captado el interés de muchos autores desde el siglo XIX como Sicardi y Cambaceres. Hay un momento de inscripción paradigmático con la aplicación del modelo realista en manos de Manuel Gálvez (Nacha Regules, 1919) quien había hecho una investigación sobre la "trata de blancas", un momento de disfraz y travestismo masculino con Versos de una... de Clara Beter (1926), seudónimo de César Tiempo. La lista se continúa a lo largo del siglo XX hasta el punto que podría trazarse una línea de novelas de/con prostitutas que fueron diseminando ideologías literarias, políticas y de género. Cuestiones que tenían que ver con regulación de una actividad, con el disciplinamiento y control de los cuerpos de las mujeres, con los modos pensar la dimensión de la moral, los afectos y el deseo femenino. Cuestiones, digamos, donde el estado se jugaba sus imaginaciones públicas y sus partidas simbólicas sobre el orden de los cuerpos, los discursos y los placeres. Creo que Beya junto con El trabajo (2007) de Aníbal Jarkowski son dos versiones actuales sobre la captura de cuerpos femeninos para hacer de ellos cuerpos de ficción en los que se juegan lecturas sobre el presente.

Estoy completamente de acuerdo. Vos escribiste un artículo clarísimo sobre el tema, no tengo nada para agregar, salvo, si te parece bien, un link con ese brillante artículo ${ }^{1}$.

¿Con qué otros textos u autores actuales encontrás afinidades literarias o estéticas ? ¿Qué otras propuestas te interesan?

Hoy siento afinidad con Pedro Mairal. Me interesa mucho lo que hizo en El gran surubí: una especie de Martín Fierro contemporáneo, una pesadilla que cruza peronismo con capitalismo salvaje, contado en sesenta sonetos y con una imaginación pletórica. Me interesó el experimento de Oscar Fariña con el Guacho Martín Fierro. Me interesa mucho lo que hizo Leonardo Oyola en Chamamé. Por fuera del terreno de las afinidades, es muy larga la lista de lo que me interesa ; me gusta lo que hacen Carlos Ríos, Selva Almada, Dalia Rosetti, Julián López, Luis Sagasti, Cucurto, no sé, creo que prefiero no hacer esta lista porque es muy extensa, me llevaría unas cuantas horas hacerla bien. Sólo en literatura argentina contemporánea creo que reúno unos cien nombres...

Uno de los capítulos de La Virgen Cabeza termina con la muerte de un niño, Kevin, en medio de una balacera en un operativo policial en la villa donde transcurre la novela. La escena remite a un lugar común de la literatura y el cine. En la tradición literaria argentina constituyen un resto significante: el puñado de huesitos del hijo de la cautiva, los niños enfermos por el contagio y la pobreza, los restos, los fetos. Son como lugares del sacrificio 
donde o a través de los cuales un "imaginario sexual nacional" persistente, como dijo María Moreno, se cobra con cuerpos infantiles sus abismos de significación.

Sí : el monstruo que se come a sus criaturas. En un país de una historia tan violenta como el nuestro, con tanto asesinato en el adentro -de la frontera, de la "patria", del partido, etc., el sacrificio del niño parece una pesadilla de lo más razonable. Tal vez por eso nos resulte tan significativa y por eso se reitere sin perder eficacia.

\section{NOTAS}

1. Cfr. Nora Domínguez, "Capturas », Escritores del mundo. Revista-blog de literatura, ensayo y crítica, Disponible en http://www.escritoresdelmundo.com/2013/06/capturas-por-noradominguez.html (N. de las editoras)

\section{AUTOR}

\section{NORA DOMÍNGUEZ}

Directora del IIEGE (Instituto interdisciplinario de Estudios de Género), Universidad de Buenos Aires 